\title{
The Cognitive Face of Cerebellum; Implications for Extended Research
}

\author{
Masoumeh Bayat', Samira Hosseinit, Fatemeh Shamsit, Mohammad Nami* \\ Department of Neuroscience, School of Advanced Medical Sciences \\ and Technologies, Shiraz University of Medical Sciences, Shiraz, Iran \\ tThese authors have made equal contribution to this report and are sorted alphabetically. \\ Use your device to scan and
read the article online
}

* Corresponding author:

Mohammad Nami,

Department of Neuroscience,

School of Advanced Medical

Sciences and Technologies,

Shiraz University of Medical

Sciences, Shiraz, Iran

Email: torabinami@sums.ac.ir

Received: 21.09.2016

Revised: 29.09.2016

Accepted: 01.10.2016

Keywords: Cerebellum, Cognitive, Cerebellar cognitive affective syndrome

\begin{abstract}
For years, the role of cerebellum was believed to be limited to motor functions. Only since almost two decades ago, a new concept about cerebellum and its contribution to non-motor functions including cognition and emotion started to emerged. During the recent years, numerous studies have focused on the cerebellar non-motor functions with their results providing supportive evidence on this view. The connections between cerebellum and cortical and subcortical areas such as frontoparietal cortices and the limbic system provide additional evidence for the involvement of cerebellum in higher cognitive functions. This review has been an effort to discuss the studies assessing different aspects of cognitive and affective disorders following cerebellar damage, as well as the cerebellar activity during cognitive tasks using novel approaches including fMRI and PET scans.
\end{abstract}

\section{doi https://doi.org/10.18869/nrip.jamsat.2.3.274}

\section{Introduction}

The cerebellum is a complex structure comprising 10 hemispheric and vermian lobules which differ in their afferent and efferent connections (1). Some of the anatomical and functional features of the cerebellum include the population of its neurons, its operation speed, its massive neural connections with the cerebral cortex, and the extensive connections of its output fibers (2). Cognitive function of the cerebellum, beyond its motor role, is now the subject of an established multidisciplinary field of investigation known as the cognitive neuroscience of the cerebellum(3). As such, in 2010, an issue of the journal 'Cortex' was dedicated to the cerebellum and cognitive functions. Many studies over the past 20 years, have prompted researchers to conclude that the cerebellum contributes to affective and higher order non-motor functions(4). The term "cerebellar cognitive affective syndrome" (CCAS) which was coined by
Schmahmann includes impairments in executive functions and disturbances in visual-spatial, and linguistic abilities, with affective disturbance ranging from emotional blunting and depression, to disinhibition and psychotic presentation. The cognitive and psychiatric components of the CCAS, together with the ataxic motor disability of the cerebellar disorders, are conceptualized within the 'dysmetria of thought' hypothesis. This concept holds the idea that cerebellar facilitates automatic modulation of the behavior around a homeostatic baseline, and the behavior being modulated is determined by the specificity of anatomic subcircuits or loops within the cerebrocerebellar system $(3,5,6,7)$.

One way in which the cerebellum might influence different cognitive functions in brain-damaged patients is through the influence of diaschisis. A number of studies have shown that damage to the cerebellum can lead to reduced metabolic activity in 
the contralateral cerebral hemisphere and elsewhere perhaps due to the loss of excitatory cerebellar input to the thalamus and forebrain structures (8).

The neuroanatomical circuits that subsurve the cognitive and affective roles of cerebellum consist of the corticoponto-cerebellar and cerebellothalamo-cortical loops which establish a close connection between the cerebellum and the supratentorial motor, paralimbic and association cortices(9). These connections suggest the contribution of cerebellum to functions such as working memory, language, emotion, etc. which are elaborated in the following sections.

\section{Methods}

Articles were identified through PubMed, Sciencedirect and Scopus databases search. Our search was performed using the following keywords without restriction of date: Cerebellum OR Cerebellar AND cognition OR working memory OR executive function, language, emotion, affective syndrome. This search yielded a large number of papers. We included 64 papers and excluded others by reviewing the abstracts. Our exclusion criteria for the retrieved papers were: 1- studies on non-human subjects, 2- Motor function of cerebellum 3- lack of dirrect cerebellar involvement.

\section{Working memory and cerebellum}

Working memory (WM) is the ability to actively maintain a limited amount of information in a readily-available state, even in the absence of continued sensory input. This capacity for internal representation is central to our complex cognition (10). It is achieved through the engagement of a widely-distributed network of cortical and subcortical areas. Regions within the frontal and parietal cortices as well as the cerebellum show increased activation in neuroimaging studies focusing on the WM(4).

Schlösser et al (2006) analyzed fMRI datasets in studies of working memory and proposed an extended network model including cerebellum for WM(11). Working memory impairments were present in a number of psychiatric disorders in which the cerebellum was implicated including addiction, anxiety, obsessive-compulsive disorder, depression, and schizophrenia (12).

Speech-specially covert-has a critical role in WM through creating and refreshing motor memory traces, allowing new information to be processed whereby the cerebellum generally supports working memory through engaging inner speech mechanisms $(10,12)$. Verbal WM problems may partly underlie the compromised performance of the cerebellar lesion patients on at least some complex cognitive tasks (2). Evidence on human lesions and brain imaging data have proposed cerebellar contribution to verbal WM $(2,12,13)$. Patients with damage to the cerebellum exhibit a selective deficit in verbal WM (4). Cerebellum has a great cognitive involvement in WM which is not confined to the phonological loop but also supporting the central executive sub-functions(14).

Neuroimaging studies have suggested a functional topography within the sub-regions of the cerebellum that subserve the verbal WM (12). The superiolateral region(10), right inferior cerebellum hemisphere $(\mathrm{VIIB})(2)$, more lateral regions of the superior cerebellum in Lobules VI and Crus I, the inferior cerebellum (Lobule VIII), the ventral dentate(12), bilateral regions of the superior cerebellar hemispheres (left superior HVIIA and right $\mathrm{HVI}$ ), portions of posterior vermis ( $\mathrm{VI}$ and superior VIIA), and the right inferior cerebellar hemisphere (HVIIB) (1) are among key regions suggested to contribute to verbal WM.

Likewise, it is reported that the cerebellar volume in healthy adults (as well as the total cerebral grey and white matter volumes) is genetically associated with WM performance (15).

\section{Cerebellum and Attention}

Higher attentional functions such as dividedattention and WM are often correlated and hence difficult to isolate from each other. They appeared to be modulated in the same part of the cerebellum, namely, the right side of the posterio-lateral portion (16).

In an investigation on the attentional and neuropsychological functions, patients with focal cerebellar lesions showed distinct deficits in qualitative aspects of divided-attention and WM tasks. The performance in the selective attention was however unimpaired(17).

Schweizer et al. (2007) provided evidence implicating the cerebellum as a critical player in the neuroanatomical network underlying visualtemporal attention (18).

There exist evidence that autistic patients and patients with acquired cerebellar lesions were similarly impaired in a tasks requiring rapid and 
accurate shifts of attention between the auditory and visual stimuli. These findings are consistent with the notion that cerebellar maldevelopment in autism may contribute to an inability to execute rapid attention shifts, and also with the proposal that the human cerebellum is involved in the coordination of rapid attentional shifts (19).

Attention deficit hyperactivity disorder(ADHD) runs in almost $5 \%$ of population in school period (20) and more than $4 \%$ in adult age (21). In ADHD, the three clusters of main symptoms include attention deficit, impulsiveness and hyperactivity. The association of ADHD with cerebellum alterations has been explored over the past decade (20).

Perlov et al. (2010) investigated the neurochemical alterations in the cerebellar neurochemistry among adult with ADHD and found a significantly increased glutamate-glutamine (GIx) to creatine $(\mathrm{Cr})$ ratios in the left cerebellar hemisphere(22).

Patients with ADHD have significantly smaller brain volumes in cerebrum and cerebellum, even after adjustment for significant covariates (23). Quantification of the cerebellar and vermal volumes from MRIs has revealed that vermal volume is significantly less among boys with ADHD. This reduction involves mainly the posterior-inferior lobe (lobules VIII to X) but not the posterior superior lobe (lobules VI to VII)(24).

On the other hand, Ravizza et al. suggested that the apparent attention-shifting deficit might be secondary to the motor demands involved in preparing, controlling, and terminating responses in high cognitive-demands. When the motor demands were reduced, the cerebellar patients showed a significant improvement upon alternating attentional tasks (25).

\section{Language and cerebellum}

A variety of linguistic disorders were found to occur following acquired cerebellar lesions. Those include impaired phonological and semantic fluency $(26,27)$, naming and word-finding difficulties $(9,13,26)$, cerebellar-induced aphasia (28), reading and writing difficulties, higher-level language deficits, including disturbed listening comprehension, impaired language proficiency and metalinguistic ability (26), central-auditory functions $(26,29)$, agrammatism $(2,9,26,29,30)$, dysprosodia (9), morphosyntactic features and the lexical access (31). The contribution of cerebellum in some higher-order linguistic processes such as speech timing, phonological aspects of lexical access, top-down mechanisms giving rise to expectations of upcoming verbal events(9), verb generation(8,32), and rhyming judgments(33) has widely been discussed.

A marked loss of functional-connectivity between the right cerebellar region and the supratentorial regulatory language areas may underlie the abnormal language function in children with ASD-LI (34).

The majority of neuroimaging studies employing non-motor language tasks typically show a lateralized involvement of ventral part of the dentate nucleus and lateral, posterior cerebellar regions (involving lobules VI-VIII) that are reciprocally linked to the supratentorial language networks of the dominant hemisphere $(2,9,35)$. They form a phylogenetically new cerebro-cerebellar system in humans which facilitate linguistic function (2).

Learning the second language can lead to increased gray matter volume in the cerebellum, a structure that has been related to processing of the grammatical rules. Additionally, GM density in the bilingual brain is correlated to the bilinguals' performance in behavioral tasks (36).

\section{The role of cerebellum in Emotion}

Recent evidence from the clinical, experimental, and neuroimaging studies suggest that cerebellum is critically involved in cognitive and emotional processes. The anatomical studies also provide supportive evidence on the connections between cerebellum and other cortical and subcortical areas associated with emotional processing including limbic system and prefrontal cortex. The emotional changes observed in patients with cerebellar syndrome and the activation of cerebellum following the emotional stimuli also support this prospect (37-39). Furthermore, the anatomoclinical analyses of cerebellum have indicated that the posterior vermis, or limbic cerebellum, is mainly involved in the regulation of emotion and affect (40). Many studies have investigated the relationship between cerebellum and emotions. In an study using functional MRI, Baumann and Mattingly found that all five primary emotions evoked activity in the cerebellum, including vermis and the intermediate parts of the cerebellar hemispheres (38). The reduced ability to experience pleasant feelings, but normal unpleasant emotions experience was found in patients with cerebellar lesions(41). Different studies on children with 
damage to the vermis showed impaired regulation of affect including irritability, impulsivity, disinhibition, and liability of affect (7). Levisohn et al. noted dramatic mood swings and uncharacteristic giddiness in patients with damage to the vermis (42). In addition, weaker emotional response to happiness-evoking stimuli has been seen in patients with cerebellar stroke relative to healthy control group (39). In the same vein, the pathological laughter and crying phenomena as an emotional disorder was found to be connected with lesions in cerebellum (43). The dysfunctional syndrome described in a 38-year-old woman who had a tumor removed from the fourth ventricle via a surgical incision in the cerebellum provide additional evidence for the contribution cerebellar damage to emotional impairment (44). Evidence for the contribution of cerebellum to some emotional deficits which occurred in chronic alcoholics found in another study (45). Evidence for reduced emotion regulation following application of slow frequency rTMS to inhibit the cerebellar activity, has also been provided (46). Moreover, the altered cerebellar function during emotion processing and theory of mind, was suggested in a review of neuroimaging studies among patients with schizophrenia (47). According to the aforementioned studies, cerebellum, and particularly its vermis, plays an important role in emotion processing and emotional regulation.

\section{Cerebellum and executive functions}

'Executive function' is a term explaining the processes needed for the conscious control of thought and emotion. The prefrontal cortex and subcortical structures are known to regulate the executive functions (48).

Numerous neuroanatomical and neuroimaging studies have proposed the relationship between the cerebellum and executive functions $(16,48,49)$. Cerebellum is now identified as a non-motor center playing a significant role in controlling of executive function such as language, visuo-spatial organization, emotional response, personality, reasoning, planning and sequencing (48). Some neuroanatomical studies show the connection between dorsolateral prefrontal cortex and neocerebellum (50). In addition, neuroimaging studies confirm that when a number of varied tasks are performed, the cerebellum and dorsolateral prefrontal cortex are activated at the same time(48). A study by Berman et al. using PET scans showed that when young adult were performing the Wisconsin card sorting test (WCST), the cerebellum and dorsolateral prefrontal cortex were activated (51). Likewise, Nagahama et al. observed a similar pattern in their study (52). Tasks demanding working memory activate both prefrontal cortex and cerebellum(48). Clinical reports have explained the executive dysfunction fallowed cerebellar damage (49). The classic executive dysfunctions are common and include impairments in set-shifting, planning, abstract-reasoning, verbal-fluency and working memory $(16,42,53,54)$. Executive function disorders are complicated and their management is challenging (48). Schweizer et al. described the use of a cognitive rehabilitation technique, Goal Management Training (a rehabilitation approach which relies on the verbally-mediated, metacognitive strategies to systematically target disorganized behavior resulting from executive and attentional impairment), in a patient with persisting executive dysfunction after right cerebellar hemorrhage $(49,55)$.

\section{The cerebellar cognitive affective syndrome}

The cerebellum has been affiliated with motor function and also necessary for the coordination of movement and balance (56). However anatomical, physiological and functional neuroimaging studies have revealed the role of cerebellum in non-motor or higher-order function (42,57). Cerebellum has connection with non-motor cortical area related to cognitive and emotional processing (58). Therefore, patients with cerebellar lesions, degeneration or stroke tend to have problem in cognitive functions associated with the cerebellar disorder itself (59). Schmahmann's syndrome represents a novel clinical condition consisting of a constellation of cognitive and affective deficits following cerebellar disease (60-62). The portrait was first described in 1998 as cerebellar cognitive affective syndrome (CCAS) on the basis of a careful neurological examination, detailed bedside mental state tests, neuropsychological investigations and anatomical neuroimaging in a group of 20 patients with focal cerebellar disorders (60).

The cerebellar cognitive affective syndrome is characterized by: 1- disturbance in executive functions including deficient planning, working memory, abstract-reasoning and decreased verbal fluency; 2- difficulties in spatial cognition such as visuo-spatial disorganization and impaired visualspatial memory; 3- personality changes including blunting of affect and 4- a language disorder featuring with agrammatism, dysprosodia and anomia(42). 
Schmahmann and Janet reported that changes in executive and visuo-spatial function with the existence of lesions of the anterior lobe of the cerebellum are minor(42).

Bonne and collogue described the cerebellar cognitive affective syndrome (CCAS) in pediatric cases of acute post-infectious ataxia (APCA). They observed patients with APCA and showed signs of disturbance in cognitive function (corresponding to CCAS) beside motor symptoms. They conclude that CCAS may be a neglected complication to APCA $(60,63)$.

In general, one may observe that the symptoms of CCAS among patient are different related to the location of the focal lesion. Tedesco reported that patients with defects in the posterior inferior cerebellar artery perform the worst in terms of cognitive functions (60).

Some case studies indicate that cognitive functions become normal and the performance may improve in a 9- and 17-month follow-up (64).

\section{Conclusion}

The importance of cerebellum involvement in motor coordination, gate and speech has been clear for years while its role in higher cognitive functions has remained less considered until recently. The emotional and cognitive impairments following cerebellar damages opened a new window to research on the cognitive implications of the cerebellum. The contribution of cerebellum in higher mental abilities such as emotion, attention, working memory and language was at first as strong as a hypothesis based on disorders observed in patients with cerebellar dysfunctions. However, the development of new technologies like fMRI and PET scans in brain research provided evidence to confirm such hypotheses. Based on the studies included in this review, the cerebellar activity is important in different cognitive functions. The topographic organization of the cerebellum reveals that any part of cerebellum is predominantly linked to a specific task. For instance, in the case of emotional regulation, the vermis has the most importance role whereas during the executive function the co-activation of neocerebellum and dorsolateral prefrontal cortex is deemed essential. Different regions of the cerebellum including superior, inferior and ventral dentate parts are proposed to be related to working memory. Language deficits in patients suffering from cerebellar malfunctions also have been anticipated in some studies.

\section{References}

1. Desmond JE, Gabrieli JD, Wagner AD, Ginier BL, Glover GH. Lobular patterns of cerebellar activation in verbal working-memory and finger-tapping tasks as revealed by functional MRI. J Neurosci. 1997 Dec 15;17(24):9675-85.

2. Timmann D, Daum I. Cerebellar contributions to cognitive functions: a progress report after two decades of research. Cerebellum. 2007:6(3):159-62

3. Schmahmann JD. The role of the cerebellum in cognition and emotion: personal reflections since 1982 on the dysmetria of thought hypothesis, and its historical evolution from theory to therapy. Neuropsychol Rev. 2010 Sep;20(3):236-60.

4. Ravizza SM, McCormick CA, Schlerf JE, Justus T, Ivry RB, Fiez JA. Cerebellar damage produces selective deficits in verbal working memory. Brain. 2006 Feb;129(Pt 2):306-20.

5. Reeber SL, Otis TS, Sillitoe RV. New roles for the cerebellum in health and disease. Front Syst Neurosci. 2013;7:83. PubMed PMID: 24294192.

6. Bastian AJ. Moving, sensing and learning with cerebellar damage. Curr Opin Neurobiol. 2011 Aug;21(4):596-601. PubMed PMID: 21733673.

7. Schmahmann JD. Disorders of the cerebellum: ataxia, dysmetria of thought, and the cerebellar cognitive affective syndrome. J Neuropsychiatry Clin Neurosci. 2004 Summer;16(3):367-78.

8. Beaton A, Marien P. Language, cognition and the cerebellum: grappling with an enigma. Cortex. 2010 Jul-Aug;46(7):811-20.

9. Marien $P$, Ackermann $\mathrm{H}$, Adamaszek $\mathrm{M}$, Barwood $\mathrm{CH}$, Beaton $\mathrm{A}$, Desmond J, et al. Consensus paper: Language and the cerebellum: an ongoing enigma. Cerebellum. 2014 Jun;13(3):386-410. PubMed PMID: 24318484.

10. Durisko C, Fiez JA. Functional activation in the cerebellum during working memory and simple speech tasks. Cortex. 2010 JulAug;46(7):896-906. PubMed PMID: 19853247.

11. Schlosser RG, Wagner G, Sauer H. Assessing the working memory network: studies with functional magnetic resonance imaging and structural equation modeling. Neuroscience. $2006 \mathrm{Apr}$ 28;139(1):91-103.

12. Marvel CL, Desmond JE. Functional topography of the cerebellum in verbal working memory. Neuropsychol Rev. 2010 Sep;20(3):271-9. PubMed PMID: 20563894.

13. Hokkanen LS, Kauranen V, Roine RO, Salonen O, Kotila M. Subtle cognitive deficits after cerebellar infarcts. Eur J Neurol. 2006 Feb;13(2):161-70.

14. Hautzel H, Mottaghy FM, Specht K, Muller HW, Krause BJ. Evidence of a modality-dependent role of the cerebellum in working memory? An fMRI study comparing verbal and abstract $n$-back tasks. Neuroimage. 2009 Oct. Ar-r.vr:(z) $\leqslant$ r; 1

15. Posthuma D, Baare WF, Hulshoff Pol HE, Kahn RS, Boomsma DI, De Geus EJ. Genetic correlations between brain volumes and the WAISIII dimensions of verbal comprehension, working memory, perceptual organization, and processing speed. Twin Res. 2003 Apr;6(2):131-9.

16. Gottwald B, Wilde B, Mihajlovic Z, Mehdorn HM. Evidence for distinct cognitive deficits after focal cerebellar lesions. J Neurol Neurosurg Psychiatry. 2004 Nov;75(11):1524-31 .PubMed PMID: 15489381.

17. Gottwald B, Mihajlovic Z, Wilde B, Mehdorn HM. Does the cerebellum contribute to specific aspects of attention? Neuropsychologia. 2003;41(11):1452-60.

18. Schweizer TA, Alexander MP, Cusimano M, Stuss DT. Fast and efficient visuotemporal attention requires the cerebellum. Neuropsychologia. 2007 Oct 1;45(13):3068-74.

19. Courchesne E, Townsend J, Akshoomoff NA, Saitoh O, YeungCourchesne R, Lincoln AJ, et al. Impairment in shifting attention in autistic and cerebellar patients. Behav Neurosci. 1994 Oct:108(5):848-65.

20. Baldacara L, Borgio JG, Lacerda AL, Jackowski AP. Cerebellum and psychiatric disorders. Rev Bras Psiquiatr. 2008 Sep;30(3):281-9.

21. Kessler RC, Adler L, Barkley R, Biederman J, Conners CK, Demler O, et al. The prevalence and correlates of adult ADHD in the United States: results from the National Comorbidity Survey Replication. Am J Psychiatry. 2006 Apr;163(4):716-23.

22. Perlov E, Tebarzt van Elst L, Buechert M, Maier S, Matthies S, Ebert $D$, et al. $H(1)-M R$-spectroscopy of cerebellum in adult attention deficit/hyperactivity disorder. J Psychiatr Res. 2010 Oct;44(14):938-43.

23. Castellanos FX, Lee PP, Sharp W, Jeffries NO, Greenstein DK, Clasen LS, et al. Developmental trajectories of brain volume abnormalities 
in children and adolescents with attention-deficit/hyperactivity disorder. JAMA. 2002 Oct 9;288(14):1740-8.

24. Berquin PC, Giedd JN, Jacobsen LK, Hamburger SD, Krain AL, Rapoport JL, et al. Cerebellum in attention-deficit hyperactivity disorder: a morphometric MRI study. Neurology. $199 \lambda$ Apr;50(4):1087-93.

25. Ravizza SM, Ivry RB. Comparison of the basal ganglia and cerebellum in shifting attention. J Cogn Neurosci. 2001 Apr 1;13(3):285-97.

26. De Smet HJ, Baillieux H, De Deyn PP, Marien P, Paquier P. The cerebellum and language: the story so far. Folia Phoniatr Logop. 2007;59(4):165-70.

27. Leggio MG, Silveri MC, Petrosini L, Molinari M. Phonological grouping is specifically affected in cerebellar patients: a verbal fluency study. J Neurol Neurosurg Psychiatry. 2000 Jul;69(1):102 6. $P$

28. Marien P, Engelborghs S, Pickut BA, De Deyn PP. Aphasia following cerebellar damage: fact or fallacy? Journal of Neurolinguistics.

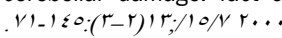

29. Walter $N$, Joanette $Y$. The unnoticed contributions of the cerebellum to language. Folia Phoniatr Logop. 2007;59(4):171-6.

30. Justus T. The cerebellum and English grammatical morphology: evidence from production, comprehension, and grammaticality judgments. J Cogn Neurosci. 2004 Sep;16(7):1115-30.

31. Fabbro F, Moretti R, Bava A. Language impairments in patients with cerebellar lesions. Journal of Neurolinguistics. 2000 7/15/;13(2 3):173-88.

32. Desmond JE, Fiez JA. Neuroimaging studies of the cerebellum: language, learning and memory. Trends Cogn Sci. 1998 Sep 1;2(9):355-62

33. Booth JR, Wood L, Lu D, Houk JC, Bitan T. The role of the basa ganglia and cerebellum in language processing. Brain Res. 2007 Feb 16;1133(1):136-44

34. Verly M, Verhoeven J, Zink I, Mantini D, Peeters R, Deprez S, et al. Altered functional connectivity of the language network in ASD: role of classical language areas and cerebellum. Neuroimage Clin. 2014;4:374-82

35. Stoodley CJ, Schmahmann JD. Functional topography in the human cerebellum: a meta-analysis of neuroimaging studies. Neuroimage. 2009 Jan 15;44(2):489-501.

36. Pliatsikas C, Johnstone $T$, Marinis $T$. Grey matter volume in the cerebellum is related to the processing of grammatical rules in a second language: a structural voxel-based morphometry study. Cerebellum. $2014 \mathrm{Feb} ; 13(1): 55-63$

37. Villanueva $R$. The cerebellum and neuropsychiatric disorders. Psychiatry Res. 2012 Aug 15;198(3):527-32.

38. Baumann O, Mattingley JB. Functional topography of primary emotion processing in the human cerebellum. Neuroimage. 2012 Jul 16;61(4):805-11.

39. Wolf U, Rapopot MK, Schweizer TA. Evaluating the Affective Component of the Cerebellar Cognitive Affective Syndrome. J Neuropsychiatry Clin Neurosci. 2009 2009;21(3):9.

40. Petrosini L, Cutuli D, Picerni E, Laricchiuta D. Cerebellum and personality traits. Cerebellum. 2015 Feb;14(1):43-6.

41. Turner BM, Paradiso S, Marvel CL, Pierson R, Boles Ponto LL, Hichwa $R D$, et al. The cerebellum and emotional experience. Neuropsychologia. 2007 Mar 25;45(6):1331-41.

42. Schmahmann JD, Sherman JC. The cerebellar cognitive affective syndrome. Brain. 1998 Apr;121 ( Pt 4):561-79.

43. Parvizi J, Anderson SW, Martin CO, Damasio H, Damasio AR. Pathological laughter and crying: a link to the cerebellum. Brain. 2001 Sep;124(Pt 9):1708-19.

44. Van Overwalle $F$, Baetens $K$, Marien P, Vandekerckhove M. Socia cognition and the cerebellum: a meta-analysis of over $350 \mathrm{fMR}$ studies. Neuroimage. 2014 Feb 1;86:554-72.

45. Fitzpatrick LE, Crowe SF. Cognitive and emotional deficits in chronic alcoholics: a role for the cerebellum? Cerebellum. 2013 Aug;12(4):520-33.

46. Schutter DJ, van Honk J. The cerebellum in emotion regulation: a repetitive transcranial magnetic stimulation study. Cerebellum. 2009 Mar;8(1):28-34.

47. Mothersill O, Knee-Zaska C, Donohoe G. Emotion and Theory of Mind in Schizophrenia-Investigating the Role of the Cerebellum. Cerebellum. 2016 Jun;15(3):357-68.

48. Powell KB, Voeller KK. Prefrontal executive function syndromes in children. J Child Neurol. 2004 Oct;19(10):785-97.

49. Schweizer TA, Levine B, Rewilak D, O'Connor C, Turner G, Alexander $M P$, et al. Rehabilitation of executive functioning after focal damage to the cerebellum. Neurorehabil Neural Repair. 2008 JanFeb;22(1):72-7.
50. Middleton FA, Strick PL. Anatomical evidence for cerebellar and basal ganglia involvement in higher cognitive function. Science. 1994 Oct 21:266 (5184):458.61

51. Berman KF, Ostrem JL, Randolph C, Gold J, Goldberg TE, Coppola R, et al. Physiological activation of a cortical network during performance of the Wisconsin Card Sorting Test: a positron emission tomography study. Neuropsychologia. 1995 Aug;33(8):1027-46

52. Nagahama Y, Fukuyama H, Yamauchi H, Matsuzaki S, Konishi J, Shibasaki $\mathrm{H}$, et al. Cerebral activation during performance of a card sorting test. Brain. 1996 Oct;119 ( Pt 5):1667-75.

53. Karatekin C, Lazareff JA, Asarnow RF. Relevance of the cerebellar hemispheres for executive functions. Pediatr Neurol. 2000 Feb;22(2):106-12.

54. Grafman J, Litvan I, Massaquoi S, Stewart M, Sirigu A, Hallett M. Cognitive planning deficit in patients with cerebellar atrophy. Neurology. 1992 Aug;42(8):1493-6.

55. Levine B, Robertson IH, Clare L, Carter G, Hong J, Wilson BA, et al. Rehabilitation of executive functioning: an experimental-clinical validation of goal management training. J Int Neuropsychol Soc. 2000 Mar:6(3):299-312.

56. Wolf U, Rapoport MJ, Schweizer TA. Evaluating the affective component of the cerebellar cognitive affective syndrome. J Neuropsychiatry Clin Neurosci r. . 9 .Summer;21(3):245-53.

57. Tomlinson SP, Davis NJ, Bracewell RM. Brain stimulation studies of non-motor cerebellar function: a systematic review. Neurosci Biobehav Rev. 2013 Jun;37(5):766-89.

58. Tedesco AM, Chiricozzi FR, Clausi S, Lupo M, Molinari M, Leggio MG. The cerebellar cognitive profile. Brain. 2011 Dec;134(Pt 12):3672 86

59. Kish SJ, el-Awar M, Schut L, Leach L, Oscar-Berman M, Freedman $M$. Cognitive deficits in olivopontocerebellar atrophy: implications for the cholinergic hypothesis of Alzheimer's dementia. Ann Neurol. 1988 Aug;24(2):200-6.

60. Manto M, Marien P. Schmahmann's syndrome - identification of the third cornerstone of clinical ataxiology .Cerebellum Ataxias. 2015;2:2.

61. Lindberg Bonne N, Evald L, Hansen JK. A case of the cerebellar cognitive affective syndrome in a 12-year-old boy with acute postinfectious cerebellar ataxia. Eur J Paediatr Neurol. 2016 May;20(3):480-2.

62. Chang C, Siao SW. Cerebellar cognitive affective syndrome: Attention deficit-hyperactivity disorder episode of adolescent with cerebellar atrophy in a psychiatric ward. Kaohsiung J Med Sci. 2 . 17 Jan;32(1):52-4.

63. Hung PL, Huang SH, Huang CC, Huang SC, Chang YC. TC-99m HMPAO brain SPECT imasing in children with acute cerebellar ataxia. Clin Nucl Med. 2008 Dec;33(12):841-4.

64. Mignarri A, Tessa A,Carluccio MA, Rufa A, Storti E, Bonelli G, et al. Cerebellum and neuropsychiatric disorders: insights from ARSACS. Neurol Sci. 2014 Jan;35(1):95-7.

\section{Submit your future research: jamsat@sums.ac.ir}

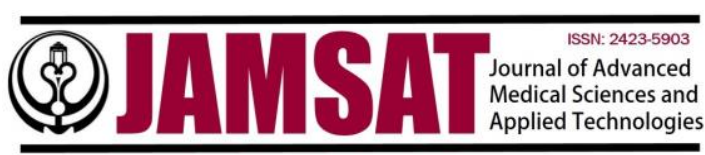

